\title{
BIOLOGY OF THE FLEA BEETLE, SCELODONTA STRIGICOLLIS MOTS. (COLEOPTERA: EUMOLPHIDAE) ON GRAPEVINE IN THE JAFFNA DISTRICT
}

\author{
BASKARATHEVAN JEYASEELAN* and GUNASINGAM MIKUNTHAN \\ Department of Agricultural Biology, Faculty of Agriculture, University of Jaffna.
}

(Received: 25 October 2001 ; accepted: 30 July 2003)

Keywords: flea beetle, grapevine, insect pest, larval instars, Scelodonta strigicollis.

Grapevine (Vitis vinifera Linn.) is widely grown in the Jaffna peninsula of Sri Lanka and provides a considerable income to growers. The yield of grapevine in Jaffna is lower than in the neighbouring countries possibly due to damage by insect pests and diseases. Of the insect pests the flea beetle, Scelodonta strigicollis (Coleoptera: Eumolphidae) is a threat to grapevine cultivation in the Jaffna district. Adults of S. strigicollis feed on the foliage and sprouting buds while the larvae feed on the roots of the vine. Hence, this study focussed on the biology of S. strigicollis for the development of suitable management strategies.

Adults of S. strigicollis were collected from affected vineyards in the Jaffna district. They were reared in the laboratory in cages enclosing a potted grapevine. Females were removed immediately after mating and reared separately to observe oviposition. The eggs laid were counted and measured. The incubation period of eggs and hatchability were determined at $31.2 \pm 0.9^{\circ} \mathrm{C}$.

Neonate larvae were reared separately in chambers and fed on fresh tender grape leaves. Larvae were examined under a stereomicroscope (x25) and their morphological features were recorded. Head capsule widths of 50 neonate larvae were measured daily from hatching to pupation using an ocular micrometer. Dyars' rule was applied to confirm the number of instars of S. strigicollis. ${ }^{1}$ Morphological features of the pupae and the pupal period were recorded. A total of 158 randomly selected adults were carefully sexed by dissection and sex ratio was calculated. Courtship behaviour of $S$. strigicollis was studied and the duration of copulation was recorded. Fecundity was determined by the number of eggs laid by each female $(\mathrm{n}=135)$.

The eggs of S. strigicollis are pale white, cigar shaped, with a smooth shiny surface. The mean length and width of eggs are $0.9 \pm 0.03 \mathrm{~mm}$ and 0.25 $\pm 0.01 \mathrm{~mm}$. Females lay eggs in groups of $22 \pm 6$ and occasionally single eggs are laid. In the field females lay eggs in the soil or underneath the split bark. In

\footnotetext{
- Corresponding author
} 
the laboratory, females laid eggs in the corners of the net rearing cages and on leaves of grapevine provided. The mean incubation period of eggs was $4.5 \pm 0.7$ days at $31.2 \pm 0.9^{\circ} \mathrm{C}$. The percentage of hatchability of eggs was $95.0 \pm 2.4$. Fecundity of $S$. strigicollis was $364 \pm 78$.

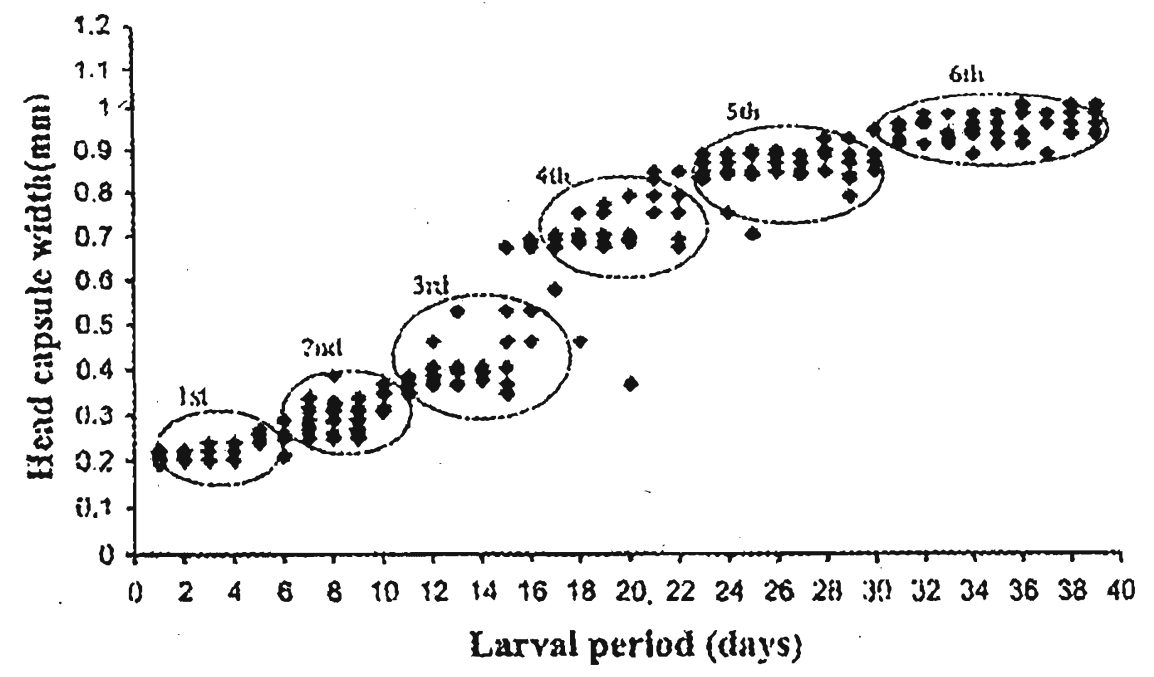

Figure 1: Distribution of head capsule widths of larval instars of Scelodonta strigicollis.

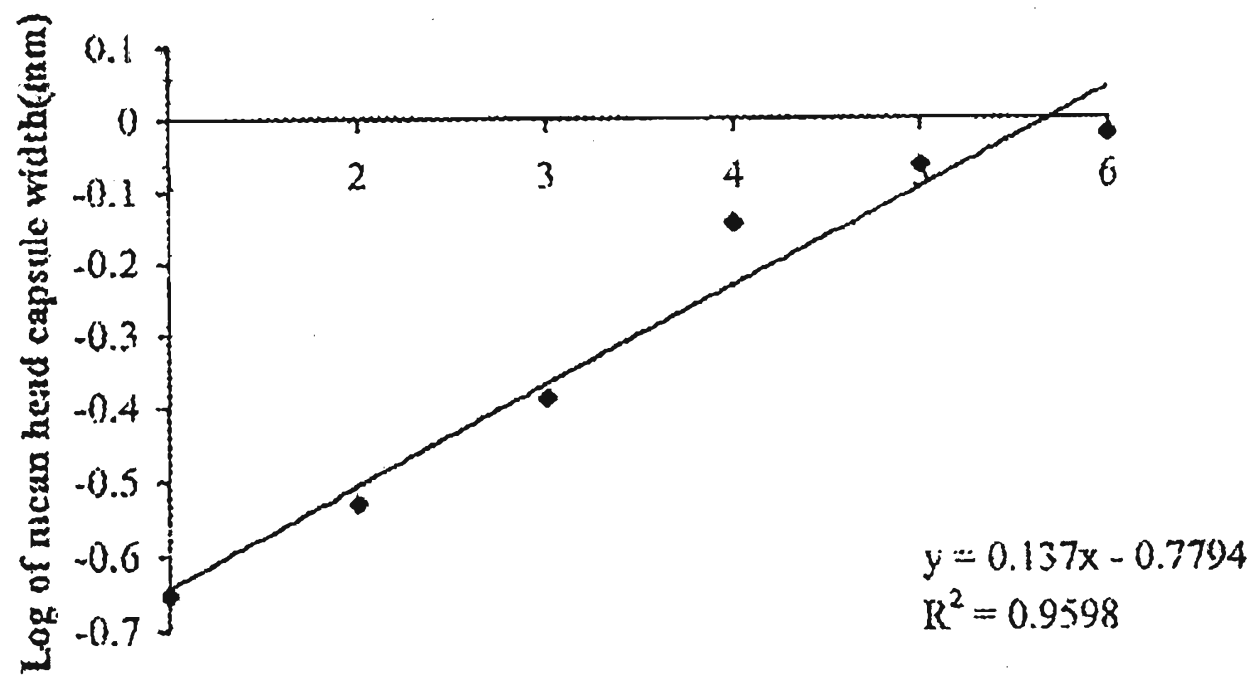

Number of instars

Figure 2: Relationship between log mean head capsule width and the corresponding larval instar of Scelodonta strigicollis. 
The head capsule widths of larvae were plotted against the age (in days) of larvae and a cluster diagram was obtained (Figure 1). The cluster diagram showed six, discrete, non- overlapping peaks, each representing an instar. Dyars' rule was used to confirm the larval stages (Figure 2 ). The regression co-efficient $\left(\mathrm{R}^{2}\right)$ was 0.9598 . Table 1 gives the head capsule width, body length and the duration of the respective instars. First instar larvae are white with a light brown head and are much more active than other instars. The final instar larvae are yellow with a dark brown head. Mean larval period was $36.9 \pm 2.3$ days at $32.2 \pm 1.2^{\circ} \mathrm{C}$.

Pupa of $S$. strigicollis are cream in colour. The mean pupal length and width were $4.2 \pm 0.2 \mathrm{~mm}$ and $2.2 \pm 0.1 \mathrm{~mm}$ respectively. Larvae pupated in the soil and the mean pupal period was $9.3 \pm 1.1$ days at $32.2 \pm 1.2^{\circ} \mathrm{C}$.

Adults of S. strigicollis are small, shiny brown with 3 prominent black patches on each elytron. The mean body length of males and females were $3.9 \pm 0.2 \mathrm{~mm}$ and $4.1 \pm 0.3 \mathrm{~mm}$ respectively. The maximum width across the abdomen was $2.1 \pm 0.1 \mathrm{~mm}$ in the males and $2.3 \pm 0.3 \mathrm{~mm}$ in the females. Sex ratio was $1: 1$. Copulation of $S$. strigicollis was observed mostly in the early evening and occasionally in the morning, 28.2 \pm 2.7 days after emergence. Copulation lasted for $15-20 \mathrm{~min}$. Pre-ovipositional period of $S$. strigicollis was $33.5 \pm 4.3$ days. S. strigicollis takes $50.4 \pm 3.6$ days at $32.2 \pm 1.2{ }^{\circ} \mathrm{C}$ to complete its life cycle.

Table 1: Head capsule width, mean body length and duration of Scelodonta strigicollis larvae.

\begin{tabular}{lccc}
\hline Instar & $\begin{array}{c}\text { Head capsule width } \\
\text { Mean } \pm \mathrm{SD}(\mathrm{mm})\end{array}$ & $\begin{array}{c}\text { Body length } \\
\text { Mean } \pm \mathrm{SD}(\mathrm{mm})\end{array}$ & $\begin{array}{c}\text { Duration } \\
\text { (days) }\end{array}$ \\
\hline 1 & $0.22 \pm 0.02$ & $1.40 \pm 0.23$ & $4-5$ \\
2 & $0.30 \pm 0.03$ & $2.87 \pm 0.19$ & $5-6$ \\
3 & $0.41 \pm 0.06$ & $4.12 \pm 0.11$ & $6-7$ \\
4 & $0.72 \pm 0.04$ & $5.02 \pm 0.24$ & $6-7$ \\
5 & $0.86 \pm 0.03$ & $5.83 \pm 0.24$ & $7-8$ \\
6 & $0.95 \pm 0.03$ & $6.27 \pm 0.32$ & $8-9$ \\
\hline
\end{tabular}

\section{References}

1. Dyar H.D. (1890). The number of moults of Lepidopteran larvae. Psyche 5:420-422. 